\title{
Teologia como desejo, diálogo e ausência: breve escopo de intersecções entre Rubem Alves e a teologia bíblica sapiencial
}

\author{
Theology as desire, dialogue, and absence: a brief \\ scope of intersections between Rubem Alves and \\ biblical wisdom theology
}

\section{Teología como deseo, diálogo y ausencia: breve escopo de intersecciones entre Rubem Alves y la teologia bíblica sapiencial}

Felipe Silva Carmo*

\begin{abstract}
RESUMO
Os textos sapienciais (Jó, Provérbios e Eclesiastes) sempre foram um desafio para a academia e, portanto, quase sempre permaneceram na periferia dos estudos bíblicos e teológicos. Com uma recente revisitação da academia, entende-se, contudo, que há necessidade de compreendê-los novamente em decorrência da fragilidade de muitos pressupostos que se levantaram com o passar dos anos. Entre tais fragilidades, há a dificuldade de elaborar uma "teologia sapiencial" que esteja em harmonia com um sistema teológico mais amplo. Com essa dificuldade em mente, este trabalho segue a hipótese sugerida por Rubem Alves de que a teologia é elaborada a partir da linguagem e propõe uma série de intersecções entre o fazer teológico deste autor com o discurso sapiencial bíblico por meio da comparação de um escopo temático comum a ambos. Por fim, entende-se a possibilidade de ler a sabedoria bíblia a partir de três perspectivas: a linguagem teológica como (1) expressão humana, (2) dialógica e de (3) ausência de Deus.

Palavras-chave: Bíblia; teologia; sabedoria; Rubem Alves.
\end{abstract}

\begin{abstract}
Wisdom Literature (Job, Proverbs, and Ecclesiastes) always represented a challenge to its students, and accordingly, it remains at the suburb of Biblical and Theological Studies. Yet, with the recent attention given to these texts, there is the understanding of the need to read them again as a result of several false presuppositions believed until now. One of the difficulties is the distress of formulating a "Wisdom Theology" that harmonizes with a broad theological sistem. Given this situation, this article holds Rubem Alves' hypothesis that theology can be elaborated from language and comes up with a number of intersections between the author's theological practice and biblical wisdom discourse by comparing both thematic scopes. A last, this work presents the possibility of reading Biblical Wisdom in light of three perspectives: the theological language as (1) human expression, (2) dialogue and of the (3) absence of God.
\end{abstract}

Keywords: Bible; theology; wisdom; Rubem Alves.

Mestre em Estudos Judaicos (2018) pela Universidade de São Paulo (USP). 


\begin{abstract}
RESUMEN
Los textos sapienciales (Job, Proverbios y Eclesiastés) siempre fueron un desafío para la académia, y por lo tanto casi siempre permanecieron en la periferia de los estudios bíblicos y teológicos. Con una reciente revisión de la académia, se entiende qué hay necesidad de comprenderlos nuevamente al encontrarnos frente al hecho de la fragilidad de muchas presuposiciones que se levantaron con el pasar de los años. Entre tales fragilidades, está la dificultad de elaborar una "teología sapiencial" que esté en armonía con un sistema teológico más amplio. Con esa dificultad, este trabajo sigue la hipótesis sujerida por Rubém Alves de que la teología es elaborada a partir de el lenguaje y propone una serie de intersecciones entre el hacer teológico de este autor con el discurso sapiencial bíblico por medio de la comparación de un objetivo temático común con ambos. Finalmente, se entiende la posibilidad de leer la sabiduría a partir de tres perspectivas: la linguaje teológica como (1) expresión humana, (2) dialógica y de (3) ausencia de Dios.

Palabras clave: Bíblia; teología; sabiduría; Rubem Alves.
\end{abstract}

\title{
Introdução
}

Embora seja comum entre biblistas afirmar a existência de um corpus sapiencial na Bíblia - isto é, um conjunto de livros que expressam a sabedoria dos hebreus -, tal afirmação, atualmente, é desacreditada com ironia e facilidade (KYNES, 2018) - ainda que seja mantida a égide "sapiencial". A partir do início do século XX, um conjunto modesto de estudiosos passa a revisitar a história hermenêutica da "sabedoria bíblica" e propõe, em tom praticamente consensual, a ineficácia e irrealidade de qualquer pressuposto a respeito da produção e recepção do corpus sapiencial (Jó, Provérbios e Eclesiastes), como havia sido estabelecido até então (WEEKS, 2007; KYNES, 2016; CARMO, 2018, p. 35-42). ${ }^{1}$ Entende-se, em suma, que estes livros não resultam, como se pressupunha, dos esforços de uma comunidade de sábios, inimiga de uma tradição profética, que apregoava uma visão de mundo quase teísta, em que a realidade é basicamente regida pela lógica de causa e efeito. Atualmente, entende-se que os autores de tais livros eram tão israelitas quanto os seus profetas, e que sua cosmovisão não apenas se relaciona ao restante da Bíblia, como, em alguns casos, interpreta e reproduz o seu pensamento em níveis intertextuais (DELL, 2015; SNEED, 2011). Preponentes dessa nova abordagem à sabedoria bíblica costumam conferir a validade de tais conclusões à aproximação dos estudiosos ao texto bíblico e à superação de pressupostos infundados, e acreditados com o passar do tempo.

Se, por um lado, os estudos bíblicos avançam no entendimento daquilo que, porventura, poderia ser classificado como "sabedoria bíblica", o mesmo não parece ocorrer do ponto de vista dos estudos teológicos. Em outras palavras, ainda se discute muito a respeito do que deve ser considerado

Podem ser incluídos aqui outros textos, comumente não aceitos pelo cânon protestante, como Eclesiástico e Sabedoria de Salomão, considerados como obras de influência helênica (CRENSHAW, 1981; MUCK, 1986). 
como "teologia sapiencial", ou mesmo a possibilidade de um fazer teológico específico, representado exclusivamente por Jó, Provérbios e Eclesiastes. Embora existam alguns consensos a respeito do assunto, permanecem ainda a ambiguidade e a imprecisão das definições, muitas vezes baseadas em pressupostos questionáveis (WEEKS, 2010, p. 107-113; CLEMENTS, 1992, p. 13-39; PERDUE, 2007; CRENSHAW, 1997). O teólogo alemão Gerhard F. Hasel, ao realizar um levantamento cronológico das abordagens teológicas aplicadas ao Antigo Testamento (AT), comenta: "virtualmente, todas as teologias do AT tiveram dificuldades de lidar com os escritos sapienciais" (HASEL, 2012, p. 62). No contexto brasileiro, o saudoso professor Milton Schwantes observa que a negligência dos textos sapienciais afetou sua elaboração teológica. Em suas palavras: "a tendência é de tais provérbios não terem grandes influências em estudos e pesquisas. Param às portas da academia. [...] a proverbialidade vai ficando de fora das coisas de religião, da teologia, da política" (SCHWANTES, 2008, p. 54). Evidentemente, essas observações não refletem apenas a negligência que os estudos bíblicos possuíam em relação ao corpus sapiencial, mas também a dificuldade de entendê-lo dentro de um escopo teológico mais abrangente.

Essa dificuldade se deve à noção de que, da perspectiva dos estudos bíblicos, os textos sapienciais sempre representaram um "estranho no ninho", no que diz respeito à história da salvação (RAD, 2006, p. 724-727). Estes livros compõem um conteúdo majoritariamente didático e moralizante, ou, em outros termos, despreocupado com os principais assuntos teológicos relacionados aos dogmas cristãos, como o pecado original, a aliança de Deus com Israel, o advento do Messias, a justificação pela fé etc. Além disso, os textos sapienciais destoam de outras composições bíblicas por apresentar uma expressão narrativa quase nula, e dar preferência ao uso criativo e poético da língua hebraica, além de discorrer por meio de pensamentos mais longos e complexos que os usuais (WILLIAMS, 1997). Tais características, embora não pressuponham de imediato a existência de uma "comunidade de sábios", alienada da religião israelita, como costumava-se argumentar, de fato expressam peculiaridades literárias quando comparadas a outros textos bíblicos.

Se, de acordo com estudos recentes, para a elaboração de uma sabedoria bíblica é impreterível recorrer ao texto para construir pressupostos e significados, é possível que as peculiaridades deste texto possam, similarmente, sugerir pistas para a elaboração de uma teologia sapiencial. Este pensamento está em paralelo à hipótese de Rubem Alves a respeito da relação entre teologia e literatura. Para o autor, "para se entender a religião, é necessário entender o caminho da linguagem” (ALVES, 2006, p. 5). Com isto em mente, 
o autor basicamente pressupõe que a gramática da linguagem costuma revelar a forma pela qual o mundo é percebido e organizado pelo ser humano. A linguagem, assim, não é apenas um meio de comunicação, mas também se constrói numa relação entre o passado e o futuro, ou seja, uma experiência histórica, material. É por isso que a aparição de uma nova linguagem poderá anunciar uma nova experiência do mundo, justamente por dar a ele as conotações próprias de uma cultura. Assim, para o ser humano, o mundo não é percebido "face a face", mas os seus olhos "são programados pela linguagem" (ALVES, 1984, p. 126). Visto que por meio das palavras a realidade é significada e construída, expressando como vive o ser humano em relação ao mundo, é possível para Rubem Alves afirmar que até a elaboração teológica passará pela linguagem para ser expressada e, portanto, extrair seu significado. A própria teologia estaria à mercê de como poderá ser expressada por meio da linguagem, tornando-se, ela mesma, uma linguagem em si. Para Rubem Alves (apud REBLIN, 2007, p. 78):

A religião é um tipo especial de linguagem. Não difere das demais linguagens em sua origem. Igualmente como qualquer outra linguagem, foi criada pelo ser humano e todos seus símbolos guardam relação com a vida prática do ser humano, isto é, com as condições em prol de sua humanização e sobrevivência.

Com o problema e a hipótese em mente, este artigo tem como principal objetivo discorrer de forma breve sobre a "teologia como linguagem humana", a partir de Rubem Alves, aplicando-a ao discurso sapiencial bíblico. A possibilidade dessa comparação foi considerada pelo autor deste trabalho durante o seu período de mestrado (CARMO, 2017a) e desenvolvida com mais tempo no âmbito do grupo de pesquisa "Análise Literária de Narrativas: Novas Metodologias para o Ensino da Interpretação Bíblica”, coordenado por Jõao Leonel, no Mackenzie, em São Paulo. Assim, para a elaboração de um referencial teórico alvesiano, o trabalho considera as produções do autor em ambos os seus períodos de formação: de teólogo da libertação a cronista do cotidiano (NUNES, 2007; CERVANTES-ORTIZ, 2005; SILVA, 2017). Ainda assim, como se encontra longe da possibilidade de oferecer um escopo do pensamento teológico de Rubem Alves - como algumas obras farão ${ }^{2}$-, o artigo pretende apenas pontuar algumas noções úteis para a relação entre teologia e linguagem, divididas preferivelmente em três pontos: (1) a linguagem teológica como expressão do ser humano no mundo; (2) a linguagem teológica como diálogo; (3) a linguagem teológica como ausência de Deus.

\footnotetext{
2 Para trabalhos que tratam a teologia de Rubem Alves de maneira mais sistêmica, ver, por exemplo: Iuri A. Reblin (2007); Leopoldo Certanves-Ortiz (2005); Antônio V. Nunes (2013), entre outros.
} 


\section{Breves considerações sobre teologia e linguagem em Rubem Alves}

Para Rubem Alves, não é possível falar de teologia sem passar pelo crivo da linguagem. O ser humano, com um ser de cultura, ao experimentar o mundo, se utilizará da linguagem para conferir a ele sentido. Assim, falar sobre o mundo ou sobre as coisas que ele contém significa "vesti-lo" gramaticalmente; fixando-se em palavras e conceitos, o ser humano estará apto para discorrer sobre sua realidade utilizando-se das ferramentas oferecidas pela língua e, por conseguinte, aparentando um sentido que lhe pareça aceitável para a existência (VELIQ, 2014; ALVES, 1984). Ainda assim, o ser humano não se contentará com o mundo que está diante dele: a linguagem tentará alcançar objetivos que transcendem a existência no mundo, na tentativa de representar uma realidade superior, mesmo que imbuída de características materiais, mundanas (ALVES, 2014, p. 17-35). Se o universo cultural que ele desenvolveu não é capaz de suprir sua necessidade de sentido, "o ser humano é capaz de projetar um mundo totalmente novo onde a sua vontade vigora" (REBLIN, 2007, p. 78). Assim, ele elabora para si uma religião, em que ela mesma "se nos apresenta como um certo tipo de fala, um discurso, uma rede de símbolos" (ALVES, 2014, p. 25) que versa à sua maneira sobre a realidade, antes incompleta. Por extensão, o ser humano também formulará para si um sistema teológico. A teologia, na tentativa de falar sobre o Deus, será capaz apenas de lhe atribuir significado pressupondo sua existência e vestindo-o de características humanas (ALVES, 1984). É nesse sentido que a teologia, para Rubem Alves, deve ser encarada como um esforço antropológico, pois é "impossível inventar algo divino sobre Deus. Só é possível inventar algo humano sobre Deus" (REBLIN, 2007, p. 66). Por estar imbuída de linguagem e, portanto, limitada ao conhecimento humano do seu próprio mundo, a teologia se limitará aos símbolos que a linguagem pode conceber dessa relação entre o ser humano e o mundo. Em seus termos,

Lá, onde quando pela primeira vez o homem emerge de uma relação indiferenciada com o mundo, lá quando nasce o homem como homem, forma-se o embrião desta linguagem de relação, que veio a se cristalizar no símbolo ou símbolos que funcionam como "Deus". [...] Há tantos deuses quantas relações existenciais do homem com o seu mundo (ALVES, 1984, p. 66).

Por outro lado, é sugestível que o esforço, ou insistência, de um fazer teológico a partir de Rubem Alves seja, em parte, contraditório aos objetivos do próprio autor. Diante da proposta de formular uma teologia - levando

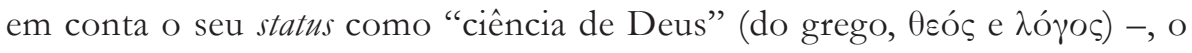
escritor poderia logo observar: "Não escrevo teologia. Como poderia escrever 
sobre Deus? O que faço é pintar com palavras as minhas fantasias - imagens modeladas pelo desejo - diante do assombro que é a vida" (ALVES, 2005b, p. 23). Ou, nos termos de Iuri A. Reblin (2007, p. 60): "a teologia, em Rubem Alves, não é e nem pode ou deveria ser, mas é, muitas vezes, aquilo que certos teólogos pretendem que ela seja". Isso ocorre porque essa teologia tomou significados imanentes em seu itinerário pessoal "Do paraíso ao deserto", em que descreve um sinuoso caminho que culminou na contemplação do humano, e não em uma urgência metafísica. Se definida em seus próprios termos, é possível que Rubem Alves pudesse pontuar que teologia: "é uma atividade para aqueles que perderam a unidade paradisíaca original, ou para aqueles que ainda não a encontraram", isto é, uma tentativa humana que permita fazer sentido ao caos; "é a tentativa do homem de ajuntar de novo as pétalas de sua flor, que é contínua e cruelmente destruída por um mundo que não ama flores"; além disso, ela "é a expressão do projeto inconsciente e sem fim que é o coração do homem: a criação do mundo com uma significação humana"; teologia é "um contemplar do hoje sob a perspectiva do futuro" (ALVES, 1984, p. 124-31; CERVANTES-ORTIZ, 2005, p. 32-40). Em suma, teologia, para Rubem Alves, é a tarefa do coração humano que responde aos fatos brutos da realidade a partir da contemplação do cotidiano; ela representa um esforço de conotação antropológica movido pelos desejos, paixões e esperanças daquele que a elabora. Aqui, expressa-se a linguagem teológica do ser bumano no mundo.

Para Rubem Alves, tudo o que o ser humano poderá dizer, e desejará dizer, sobre o mundo parte da urgência exigida de seu corpo. Este, composto de incontáveis necessidades e privações, se utilizará da teologia para dar significado à sua maneira de ser no mundo. É nesse sentido que o corpo se torna, dentro de suas limitações, uma representação do divino, por meio da qual se elabora uma teologia para a existência, de forma que "o transcendente já está disponível na realidade natural” (ALVES apud NUNES, 2013, p. 56). Em paralelo às demandas do corpo, serão significadas também todas as suas experiências, físicas e psicológicas:

Todas as reflexões teológicas são, lá no fundo, reflexões sobre o corpo, sobre o corpo que espera, sobre o corpo que angustia, sobre o corpo que sofre, sobre o corpo que sente, sobre o corpo que ama. Assim, a teologia conduz o ser humano até às entranhas e às fronteiras de seu próprio corpo, expressando suas esperanças e seus desejos (REBLIN, 2007, p. 66).

O corpo, contudo, não está só: ele encontra-se inserido, e de alguma forma substanciado, no ambiente em que vive através da história. Assim, para Rubem 
Alves, Deus agirá no ambiente e na história humana, porque o próprio ser humano não pode se alienar destes. O mundo e o humano não se interpretam como duas entidades estranhas, que se contrapõem uma à outra: "o mundo humano também começa com o corpo [...] foi engendrado em meio à sua luta para sobreviver. Todas as invenções humanas foram criadas pelo corpo e em benefício deste corpo" (ALVES, 1987, p. 35). Por isso, ao transformar a natureza, o ser humano estará, inevitavelmente, transformando a extensão do seu corpo: "o mundo é uma extensão do corpo. É a vida: ar, alimento, amor, sexo, brinquedo, prazer, amizade, praia, céu azul, auroras, crepúsculos, dor, mutilação, impotência, velhice, solidão, morte, lágrimas, silêncios" (ALVES, 2005c, p. 32-33). A teologia de Rubem Alves não pode abandonar o mundo, mas inevitavelmente partirá dele, visto que "não se pode falar de Deus sem o mundo nem do mundo sem Deus” (NUNES, 2013, p. 34).

Como linguagem, a teologia estipulará para si regras e "limites gramaticais". Rubem Alves entenderá que, antes de iniciar uma conversa a respeito de teologia, "temos de tomar consciência de quem é que estabelece as regras do jogo" (ALVES, 1984, p. 29). O autor, a princípio, contudo, não tenta estabelecer suas próprias regras para o jogo, mas sugere uma opção a ser evitada: da sua perspectiva, uma teologia não deve olhar para si como a única experiência absoluta; nos termos de Lutero, um cor incurvatum in se ipsum ("um coração encurvado sobre si mesmo"). Ao contrário, teologia "trata-se de um esforço para conquistar a biografia por meio da história. É um esforço para ampliar os 'outros relevantes' com quem estamos em conversação, a fim de ir além dos limites estreitos em que a nossa biografia nos aprisionou" (ALVES, 1984, p. 28). De maneira mais específica, a linguagem da teologia se faz, em diálogo; em seus termos, em "embates" ou "batalhas" com o outro. Rubem Alves declara que a única regra que estabeleceria ao jogo é a de que todas as estórias dependem uma das outras. A teologia se faz em face a um horizonte de possibilidades que, embora demasiado amplo, oferece ao coração humano um senso de direção: "Segundo a entendo, a teologia cristã é nada mais e nada menos que uma conversação sobre a vida que ocorre na medida em que ouvimos as vozes e contemplamos os horizontes do mundo bíblico" (ALVES, 1984, p. 30). A escolha entre um horizonte a outro se dá, para o autor, apenas em questão de amor e esperança.

Essa noção a respeito da teologia, é possível, pode ser equiparada ao conto "O galo", em Teologia do Cotidiano (ALVES, 1994, p. 58-61; cf. MENDES; PY, 2018, p. 12-17). Neste conto, Rubem Alves narra a história de um galo orgulhoso que, ao som de seu despertador, acordava todas as manhãs para cantar e, como resultado de seu canto ("Co-co-ri-có”), fazia nascer o 
sol para um novo dia. Certa ocasião, o galo perde a hora, o despertador não toca, e ele acorda espantado, pois o sol nasceu independentemente de seu canto. O galo entra em depressão. Ele consulta sua psicanalista, a coruja, que o encoraja a jogar fora o despertador diante da descoberta. Embora demore, o galo finalmente entende que o sol não precisa do seu canto para nascer, e que poderia viver de forma mais tranquila. Rubem Alves, na estória, explica que "os galos não gostam de polifonia, gostam mesmo é do seu canto só", visto que "pelo vale afora havia galinheiros que não acabavam mais, cada qual com seu galo, e cada galo cantava de um jeito diferente" (ALVES, 1994, p. 59 e 58). É neste ponto que o autor parece refletir seu entendimento de que a teologia só é possível quando considera o diálogo, o outro relevante, já que para ele: "o sistema [...] a fim de se manter e de se expandir, precisa permanecer global. Consequentemente, seu maior inimigo é tudo aquilo que o nega, que se coloca contra ele, que se recusa a tornar-se parte sua" (ALVES, 2005a, p. 69). O autor mesmo explica a estória em seus termos:

Espero que tenham percebido que essa estória é uma parábola teológica sobre uma das coisas mais lindas do evangelho, que diz que Deus é como o Sol que nasce sobre os justos e injustos, ou como a chuva que cai sobre maus e bons. Eu sei que isso parece injustiça, pois o certo seria que o Sol brilhasse só sobre os bons. O certo seria se a fonte, quando o malvado chega perto, secasse. O certo seria se a chuva só caísse sobre os justos (ALVES, 1994, p. 60).

Ao relatar sua experiência biográfica e teológica, Rubem Alves também entende que a linguagem teológica se faz em virtude da ausência de Deus, ou "teologia da morte de Deus" - uma teologia que parte do pressuposto da consciência de uma ausência do objeto que lhe confere conteúdo (ALVES, 1984, p. 59-68; MARTINS; ALMEIDA, 2013). A princípio, Rubem Alves explica que os animais não sentem ausência: eles passam pelo mundo, de geração a geração, sabendo exatamente o que necessitam para viver, sem que ninguém os eduque. A natureza impôs a seus corpos o necessário para sobreviver ao mundo sem a necessidade de imaginar soluções: "O homem, diferentemente do animal que é seu corpo, tem seu corpo. Não é o corpo que o faz. É ele que faz seu corpo" (ALVES, 2014, p. 18-19, grifo do autor). O ser humano, ao contrário dos animais, sente a ausência de roupa, comida, abrigo etc.; essa necessidade o impele ao desejo e, por consequência, à ausência e à necessidade da imaginação. Nas palavras de Rubem Alves, "O homem é um ser de desejo. Desejo é sintoma de privação e ausência” (ALVES, 2014, p. 21). De maneira semelhante, a prática da religião corresponderia uma resposta humana à ausência de sentido; através dela, o ser humano é capaz de conferir signifi- 
cados a elementos materiais - e a si mesmo -, a fim de conquistar algo que transcenda a sua existência física. "Aqui surge a religião, teia de símbolos, rede de desejos, confissão de espera, horizonte dos horizontes, a mais fantástica e pretenciosa tentativa de transubstanciar a natureza" (ALVES, 2014, p. 24).

Ainda em paralelo à noção dos símbolos da ausência humana e sua necessidade de produzir conhecimento e significado, Rubem Alves se utilizará do entendimento de Ludwig Feuerbach (1957) para afirmar a linguagem da teologia como ausência de Deus: o ser humano como "ateu porque religioso", ou a teologia como a "morte de Deus" (ALVES, 1984, p. 59-67). Esse obituário, contudo, não declara a morte eterna e literal do Deus judaico-cristão. O que o autor constata é que as estruturas de pensamento e de linguagem que formulavam este Deus entraram em colapso, ou tornaram-se caducas. A partir do movimento que se iniciou no séc. XIII, "o homem aprendeu a lidar com todas as questões de importância sem recorrer a Deus como uma hipótese fundamental", em outras palavras: "cada vez se torna mais evidente que tudo funciona normalmente sem Deus" (BONHOEFFER apud ALVES, 1984, p. 60-61). Diante da dificuldade de conferir a Deus relevância às novas demandas mundanas - e a declarada percepção de uma ausência de sentido -, o ser humano passa a dar à luz outro Deus. Isto é, passa a formular, por meio da sua linguagem, e inevitável experiência com o mundo, novas projeções da divindade a partir daquilo que julga necessário: Deus "é o diário onde o homem registra os seus mais altos pensamentos e sentimentos, o álbum genealógico onde inscreve o nome das coisas que lhe são mais caras, sagradas" (FEUERBACH apud ALVES, 1984, p. 63). ${ }^{3}$ Neste sentido, a tarefa linguística da teologia passa a ser uma tarefa essencialmente antropológica; e o teísmo torna-se o precursor do pensamento teológico. Nos termos de Rubem Alves:

Deus morreu. Mas ele nasceu também. Nasceu como parte da história do homem, como símbolo que as culturas criaram para fazer sentido do seu mundo. Sua morte, portanto, é um evento, não da história dos deuses, mas da história do próprio homem. Foi o homem que mudou. [...] Não foi Deus que morreu, mas o homem que um dia fez uso desta palavra para orientar-se no mundo (ALVES, 1984, p. 66-67).

É possível que a ideia de uma teologia que "não fala de Deus" possa ser observada em uma das experiências de Rubem Alves, "Sobre deuses e rezas”, em Teologia do Cotidiano (ALVES, 1994, p. 54-57; MENDES; PY, 2018,

\footnotetext{
Esta mesma noção da morte de Deus é relatada por Rubem Alves na ocasião daquilo que Leopoldo Cervantes-Ortiz (2005, p. 36) enumerou como sua "terceira ruptura", ou seja, "a ruptura com a imagem de Deus". O próprio Rubem Alves descreve o momento com os mesmos termos: "Mas nossos deuses morreram. Ou, se não morreram, ficaram mudos e silenciosos” (ALVES, 1984, p. 17).
} 
p. 9-12). Nesta experiência real, o autor, no aeroporto, se depara com uma conhecida. Ela está inquieta: permanece falando com diversos desconhecidos e, ao perceber um pequeno sinal de desprezo, passa para outro. Rubem Alves nota que ela, com uma Bíblia nas mãos, pretende falar de Deus às pessoas e, assim, salvar suas almas. Reconhecendo sua familiaridade e chamando-a pelo nome, ambos iniciam uma conversa em que a senhora questiona se o autor ainda permanece firme na fé. Rubem Alves não apenas responde à questão de maneira parabólica, mas, na tentativa de provocá-la, questiona sua necessidade de falar de Deus initerruptamente, afirmando: "Pois Deus é como o ar. Quando a gente está em boas relações com ele não é preciso falar. Mas quando a gente está atacado de asma, então é preciso ficar gritando pelo nome dele" (ALVES, 1994, p. 56). No fim, ele conclui: "quem fica o dia inteiro atrás dele [de Deus], com falatório, é porque desconfia dele" (ALVES, 1994, p. 57). Nesta ocasião, é possível que o autor entenda a relação do ser humano com Deus de uma perspectiva quase teísta: não há necessidade de convocá-lo a todo momento para afirmar o que é da responsabilidade divina ou humana; basta reconhecer os espaços de atuação de ambos.

\section{Intersecções entre a teologia do cotidiano e o discurso sapiencial}

A primeira relação do discurso bíblico sapiencial com as considerações teológicas de Rubem Alves encontra-se no âmbito da linguagem teológica como expressão do ser humano no mundo. Isto é, na ideia de que a sabedoria expressa, acima de tudo, o desejo e os anseios humanos sobre a vida comum. Uma consideração mais declarada sobre esse aspecto nos sapienciais é entendida por Gerhard von Rad (2006), em seus volumes da Teologia do Antigo Testamento. Nessa ocasião, o autor separa uma seção específica para a sabedoria bíblica, intitulando-a como "Israel diante de Javé (a resposta de Israel)". Com isso em mente, Rad argumenta que o discurso sapiencial - por estar desinteressado na história da salvação - tenta promover uma resposta humana às ações divinas, que, neste caso, estariam mais claras em outros contextos da Bíblia: "Javé não havia escolhido para si o seu povo como objeto mudo da sua vontade histórica, mas para o diálogo" (RAD, 2006, p. 345). Nesse sentido, o autor sublinha a possibilidade de que, nos outros contextos, Deus fala ao ser humano através da revelação profética; no discurso sapiencial, o ser humano fala a Deus por meio da poesia, do provérbio e da lamentação. Em outras palavras:

As palavras de Deus aos seres humanos, enfatizadas em algumas partes da Bíblia, encontram seu complemento nas palavras direcionadas à Deus em outras partes. Deus e os seres humanos, por assim dizer, conversam um com o outro. Nenhum destes dois lados da conversação é prioridade em relação ao outro, embora a organização do cânon privilegie a revelação divina (BUSS, 2007, p. 14, tradução livre). 
Como resposta humana, é natural que o discurso sapiencial abrangesse toda sorte de sentimentos relativos à humanidade - dos mais sensatos aos mais sombrios. Rad (2006, p. 346, grifo nosso) completa sua visão com a seguinte declaração: "se é possível elaborar uma antropologia teológica, será nesse ponto que se pode esperar encontrar os seus traços básicos [...] irá aparecer a imagem do ser humano diante do Deus vivo". É dessa perspectiva que o discurso sapiencial poderá conferir atenção ao que Rubem Alves entende como uma teologia que considera o corpo humano: a sua relação com a angústia, a alegria, o sofrimento, a sexualidade, a frustração etc. Mesmo de uma perspectiva estreitamente humana, "os escritores da sabedoria compreendiam a esfera do encontro entre o humano e o divino como a vida real ordinária" (CERESKO, 1999 , p. 3, tradução livre). O louvor humano não precisa estar relacionado estreitamente aos bendizeres de Israel sobre os atos heroicos e salvíficos de Deus. Para Rad, "no antigo Israel esse louvor podia assumir funções de confissão sob múltiplas formas” (RAD, 2006, p. 347). O autor, então, faz referência ao verbo hebraico הָדָ (chadah), geralmente traduzido por "louvar", mas que poderia assumir significados como "confessar", "reconhecer", "aprovar", isto é, ele insere o "louvor" dentro do alcance semântico que também poderia abranger sentimentos humanos mais complexos.

É possível que essa leitura antropológica, corporal, dos sapienciais possa esclarecer o aspecto "irreverente" de suas declarações. Em Eclesiastes, por exemplo, há o monólogo livre de qualquer interferência externa que pretende avaliar a legitimidade da vida através da experiência pessoal do seu autor (Ec 1,1-3; 4,1-4); em Jó, encontramos um discurso aberto, "palavras de um desesperado" a respeito do suicídio (Jó 3,1-26; 7,1-21) e a desconfiança da bondade de Deus (Jó 10,1-22; 16,1-22); há também a tentativa desesperada do protagonista de fazer-se entendido por seus amigos, ao alegar ser justo e, mesmo assim, vítima de incontáveis calamidades enviadas pelo próprio Deus - noção muitas vezes desconsiderada pelos próprios leitores (CLINES, 2004). Em todos esses casos, o ser humano parece dar livre expressão às suas demandas e desejos; não parece existir nenhuma aparente tentativa de ocultar o que, atualmente, poderia ser considerado como ateísmo ou ceticismo por parte dos autores bíblicos. Citando um último exemplo, os Provérbios estão meramente preocupados com situações cotidianas, abordando assuntos que poderiam ser facilmente classificados como irrelevantes para um texto sagrado, como a prudência na maneira de falar, principalmente quando à presença de pessoas ilustres ( $\operatorname{Pv} 10,11 ; 19,18 ; 10,14 ; 26,7 ; 10,32 ; 23,1-3 ; 25,16 ; 6,8$ ); o cuidado e importância conferida à vida animal ( $\mathrm{PV}$ 9,1-2; 12,10; 27,23); o respeito e dedicação à tradição, e o ensinamento dos mais idosos ( $\mathrm{Pv}$ 10,1; $4,20 ; 15,20 ; 23,19 ; 1,8 ; 4,10)$; entre muitos outros. 
Os livros sapienciais apresentam também o ideal de Rubem Alves para a linguagem teológica como diálogo. É consenso inequívoco nos estudos bíblicos que a literatura de sabedoria não apenas troca informações com textos sapienciais de outras culturas do Antigo Oriente Médio (AOM), mas chega a repetir provérbios e admoestações semelhantes - com mudanças singelas de um elemento cultural ou outro (GAMMIE; PERDUE, 1990; PERDUE, 2008; CLIFFORD, 2007). As narrativas bíblicas já deixam evidência sobre a universalidade e dialogicidade da sabedoria quando declara, a respeito de Salomão: "Era a sabedoria de Salomão maior do que a de todos os do Oriente e do que toda a sabedoria dos egípcios. Era mais sábio do que todos os homens, mais sábio do que Etã, ezraíta, e do que Hemã, Calcol e Darda, filhos de Maol; e correu sua fama por todas as nações" (1Rs 4,30-31). O discurso sapiencial, assim, parece englobar uma espécie de conhecimento popular entre as culturas do AOM; um espaço em que os povos tinham oportunidade de trocar experiências comuns. Na metáfora utilizada por Kathleen O’Conner (apud CERESKO, 1999, p. 13-14, tradução livre), a relação dialógica da sabedoria no AOM é muito bem expressa através da ideia da "feira":

Além de servir como local de troca de produtos e alimentos comuns necessários para o sustento diário, a feira também funcionava como ponto de encontro para a comunidade. Ali os amigos se encontravam, notícias eram trocadas e decisões legais e políticas eram realizadas. Espaços movimentados e abarrotados de gente, cheios de ruídos e cheiros, as feiras comportavam a vida na sua forma mais promissora e mundana. Nelas, acordos eram feitos, fortunas eram conquistadas e perdidas, e pessoas lutavam pela sobrevivência. [...] Como imagem poética e teológica, a feira expressa a fascinação dos sábios com a existência humana ordinária. Ela representa o local em que os seres humanos lutam para lidar com o caos diário [...] onde o divino e o humano se encontram.

Nesse contexto, a sabedoria bíblica expressa a linguagem teológica como diálogo por meio de discursos diretos provenientes de personalidades declaradamente estrangeiras - isto é, não israelitas. Esse fator deixa claro que "Israel também dependia da sabedoria do povo do oriente" (DAY, 1995, p. 55, tradução livre). Provérbios 30,1, por exemplo, introduz uma oração

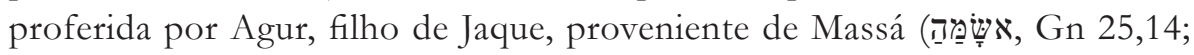
1Cr 1,30), uma personalidade estrangeira que, no contexto, soma ao conteúdo sapiencial bíblico. Outro exemplo semelhante, ainda no livro de Provérbios,

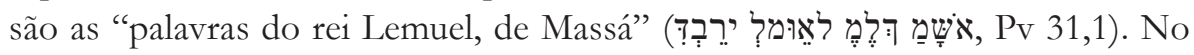
livro de Jó, após os episódios da disputa entre Deus e Satan, são introduzidas outras personagens: os "amigos de Jó", cada um advindo de uma localidade distinta. Há a possibilidade de que cada um deles pudesse representar, a partir de seu local de origem, uma cultura sapiencial renomada na época: 
"Elifaz, o temanita; Bildade, o suíta; e Zofar, o naamitita" (Jó 2,11). A Além desses exemplos, há também a sugestão de que Provérbios 22,17-24,22 não apenas replique o conteúdo de um texto egípcio intitulado Ensinamentos de Amenemope, mas também se remeta ou reproduza a obra a partir de uma perspectiva israelita (ver CARMO, 2017b, p. 185-198). Provérbios 22,17-24,22, por exemplo, é introduzida de maneira ambígua, atribuindo o conteúdo do

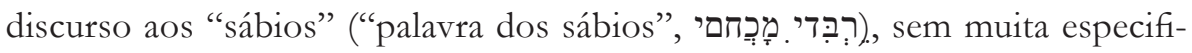
cação étnica. Ademais, em determinado momento, o texto parece fazer uma conexão intertextual com seu similar egípcio, já que ambos fazem menção à composição de "trinta capítulos" ou "trinta conselhos" (Amenemope xxvii, 5 e 10; Pv 22,20). Desta perspectiva, entende-se que a linguagem teológica sapiencial bíblica apresente um aspecto dialógico extremamente participativo, unificando a teologia israelita a outras comuns à sua época.

De outra maneira, o diálogo teológico também ocorre através de discursos indiretos, por meio de consensos compartilhados entre as culturas diferentes do AOM. Entre Israel, Egito e Mesopotâmia parecia existir certa "sinergia sapiencial" em prol de uma práxis religiosa moralmente correta. Isso significa que os participantes do discurso sapiencial do AOM partilhavam de ideias antropológicas muito semelhantes, embora de perspectivas teológicas distintas (ver alguns paralelos em MATTHEWS; BENJAMIN, 2006). Alguns poucos exemplos podem ser citados:

Israel

"Alegra-te, jovem na tua juventude, e recreie-se o teu coração nos dias da tua mocidade; anda pelos caminhos que satisfazem ao teu coração e agradam aos teus olhos; sabe, porém, que de todas essas coisas Deus te pedirá contas. Afasta, pois, do teu coração o desgosto e remove da tua carne a dor, porque a juventude e a primavera da vida são vaidade" (Ec 11:9-10).
Egito

"Meu ba interrompe: Você é humano, não divino. Seu dever é aproveitar a vida ao máximo [...] Ouve-me! Eis que é bom para um homem quando ele ouve. Sê alegre um dia, não te preocupes" (Diálogo de um homem com seu Ba, 30-65).

\section{Mesopotâmia}

“Quanto a você Gilgameš, mantenha sua barriga farta, continue se divertindo, dia e noite! Esteja contente todos os dias, dance e brinque dia e noite! Mantenha suas roupas limpas! Mantenha sua cabeça lavada, que você se banhe com água! Atente para o pequenino que segura sua mão! Que sua esposa desfrute de seu abraço contínuo! Esse é o destino [dos seres mortais]" (Épico de Gilgameš, iii, 1-15).

4 Samuel Terrien (1994, p. 73) explica: “Elifaz, cujo nome significa talvez 'Deus esmaga', era edomita, originário de Temã, centro renomado de sabedoria. [...] É possível que os nomes dos amigos, como também de Jó, tenham tido para os ouvintes da época arcaica uma significação simbólica". Veja a discussão sobre a sabedoria em Edom em Crowell (2008). 
“Todos vão para o mesmo lugar; todos procedem do pó e ao pó tornarão" (Ec 3:20).

"Não te precipites com a tua boca, nem o teu coração se apresse a pronunciar palavra alguma diante de Deus; porque Deus está nos céus, e tu, na terra; portanto, sejam poucas as tuas palavras" (Ec 5:2)

"Eis que clamo: violência! Mas não sou ouvido; grito: socorro! Porém não há justiça. $\mathrm{O}$ meu caminho ele fechou, e não posso passar; e nas minhas veredas pôs trevas. $\mathrm{Da}$ minha honra me despojou e tiroume da cabeça a coroa. Arruinou-me de todos os lados, e eu me vou; e arrancou-me a esperança, como a uma árvore. Inflamou contra mim a sua ira e me tem na conta de seu adversário. Juntas vieram as suas tropas, prepararam contra mim o seu caminho e se acamparam ao redor da minha tenda. Pôs longe de mim a meus irmãos, e os que me conhecem, como estranhos, se apartaram de mim. Os meus parentes me desampararam, e os meus conhecidos se esqueceram de mim. Os que se abrigaram na minha casa e as minhas servas me têm por estranho, e vim a ser estrangeiro aos seus olhos. Chamo o meu criado, e ele não me responde; tenho de suplicar-lhe, eu mesmo. O meu hálito é intolerável à minha mulher, e pelo mau cheiro sou repugnante aos filhos de minha mãe. Até as crianças me desprezam, e, querendo eu levantar-me, zombam de mim. Todos os meus amigos íntimos me abominam, e até os que eu amava se tornaram contra mim” (Jó 19:7-19).
"Seres humanos são argila e palha; a assembleia divina é o seu escultor" (Ensinamentos de Amenemope, xxiv, 8-20).

"Olha o que está diante de ti [mas] não mires [o dono] com insistência, [pois isso] o agride e ofende o seu ka. Não lhes fales até que ele se volte a ti, pois não se sabe o que pode desagradá-lo" (Ensinamentos de Ptabhotep, 7, vi 10 -viii 1$)$.

"Repara, repugnante é meu nome, repara, mais do que o cheiro da carniça nos dias de verão com o Sol escaldante. Repara, repugnante é meu nome, repara, [mais do que o cheiro dos] peixes em dia de pesca com o Sol escaldante. Repara, repugnante é meu nome, repara, mais do que o cheiro de uma ninhada de patos, mais do que uma moita de juncos cheia de excremento de aves. Repara, repugnante é meu nome, repara, mais do que o cheiro dos pescadores, mais do que charcos ondem pescam. Repara, repugnante é meu nome, repara, mais do que o cheiro dos crocodilos, mais do que os bancos de areia onde ficam. [...]

A quem posso falar hoje? Os irmãos são perversos, os amigos de hoje não gostam [uns dos outros]. A quem posso falar hoje? Os corações são cobiçosos, todos roubam as coisas do vizinho. A quem posso falar hoje? A doçura pereceu, a violência agride a todos. A quem posso falar hoje? [Todos] estão contentes com a maldade, a bondade é jogada no chão em toda parte" (Diálogo de um homem com seu Ba 85-95; 100-110).
"A poeira do túmulo devora a sua presa. A morte come o que ela quiser com ambas as mãos" (Estórias de Baal e Anat, CTA, 5.i 15-35).

"Escolha cuidadosamente suas palavras para ensinar alguém; a palavra é mais forte do que a espada" (Ensinamentos de Abikar, dito 16, vii, 99).

"Ele me puniu de forma abrupta, depois me deu a vida. Eu ensinarei o povo; eu instruire a terra sobre o temor [...] Ele tirou o anjo benevolente que andou do meu lado. Meu espírito protetor estava assustado para procurar outra pessoa. Meu vigor foi tirado, minha aparência viril ficou sombria. Minha dignidade voou, minha capa saltou. Sinais assustadores me assediam. Eu fui expulsado da minha casa, eu vaguei pelo mundo. Meus presságios estavam confusos, eram anormais todos os dias. [...] Meu irmão se tornou meu inimigo; meu amigo se tornou um demônio maligno: meu camarada me denunciaria com selvageria; minha melhor amiga me arrancaria a vida. Meu escravo me amaldiçoou abertamente na assembleia de cavalheiros. Minha escrava me difamou diante da multidão. [...] Eu chamei a meu deus, ele não mostrou seu rosto. Rezei a minha deusa, ela não levantou a cabeça (Ludlul bèl nèmeqi, 38-39; 45-51; 84-90).

Por fim, o discurso sapiencial também parece se aproximar de Rubem Alves quando se trata da linguagem teológica como ausência de Deus. Desde muito 
cedo nos estudos bíblicos, ao discurso sapiencial foram atribuídas características "racionalistas" ou "humanistas" (KYNES, 2016). Com isso, seus primeiros leitores compreendiam que os sábios, ao desenvolverem sua teologia, procuravam desconsiderar a ação divina e a basear suas reflexões apenas na razão humana. Orvid S. Rankin (1954, p. 3, tradução livre), por exemplo, afirma: "a literatura sapiencial deve ser considerada como os documentos humanistas de Israel [...] visto que a sua característica geral é o reconhecimento da responsabilidade moral do ser humano". A noção extrema dessa alegação - de que os textos sapienciais não se preocupam com a revelação divina -, contudo, não é acreditada atualmente. Ainda assim, existe, entre os biblistas, a ideia de que a sabedoria bíblica está mais preocupada com as ações humanas do que com a interferência divina, apenas porque pretendem conferir mais ênfase a um aspecto da cosmologia israelita (ver SNEED, 2011). Para Annette Schellenberg (2016, p. 138, tradução livre),

o pressuposto de que a ordem do mundo não mudará está relacionado à visão conservadora da sociedade; e a epistemologia dos livros sapienciais é congruente com seu foco na criação/ordem inerente no mundo (empiricismo) e sua desconsideração à história de salvação israelita.

Assim, embora possua um discurso claramente religioso, com considerações a respeito das ações de Deus na vida humana, essas ações parecem estar mais relacionadas à vida comum, desassociadas da história da salvação - ao menos de maneira imediata (cf. RAD, 2006, p. 724-727): (1) não há uma preocupação declarada a respeito da aliança divina, estabelecida com Abraão e mediada pelos patriarcas e profetas; (2) não existem discursos escatológicos mais complexos a não ser a ideia de que Deus fará justiça ao ser humano (por exemplo, não falam sobre a conquista de uma terra prometida ou sobre o julgamento e destino final ímpios); (3) não apresentam evidência de uma esperança messiânica, ou qualquer possibilidade de redenção advinda da realeza israelita; (4) não possuem referências à adoração ou visitação periódica ao templo ou à necessidade de cumprir com rituais de expiação; (5) não enfatizam a preocupação monoteísta da soberania de Deus em comparação à ineficiência dos deuses de outros povos; (6) não conferem atenção à guarda de mandamentos específicos, a não ser ao conselho proveniente da experiência dos pais (que poderá ou não possuir ligações com o decálogo); (7) embora enfatizem a ação de Deus como criador, não se remetem ao relato da criação em si, ou à entrada do pecado na família humana; entre muitos outros temas.

Em detrimento dessa possível intuição teísta de ausência divina, o nome de Deus é compreendido de maneira distante no discurso sapiencial, relegado 
a conceitos generalizados, populares tanto em Israel quanto no AOM (ver BOSTRÖM. 1990; PREUSS, 1981; SILVA, 2016). Valmor da Silva (2016, p. 890-908) realiza um interessante paralelo entre a visão de Deus em Provérbios e sua relação com a cultura popular brasileira. Já no início de suas considerações o autor reconhece: "como seus nomes são múltiplos, ele não se deixa aferrar, apenas permite representações simbólicas [...] as palavras balbuciadas podem captar indícios de sua presença no mundo” (SILVA, 2016, p. 891). Assim, Deus recebe diversificados nomes na Bíblia e é, inclusive, descrito por meio de inúmeros símbolos metafóricos (Senhor, Rocha, Criador, Pastor, Altíssimo, Todo Poderoso etc.). A maioria dos nomes e símbolos atribuídos a Deus, entretanto, não ocorrem em Provérbios, e os mais frequentes parecem

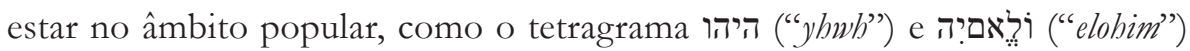
(BOSTRÖM, 1990, p. 33-34; PREUSS, 1981, p. 338). De uma perspectiva mais geral, segundo Horst D. Preuss, em Provérbios: "Javé é principalmente quem mantem equilíbrio entre comportamento e sorte dos homens"; assim, "quanto ao comportamento humano perante Javé, descrito nos antigos textos sapienciais, o assunto predominante é o temor de Javé e também em grau menor, a confiança nele" (PREUSS, 1981, p. 316). Por representarem noções muito generalizadas sobre Deus, em comparação às inúmeras utilizações encontradas no AT, o autor reconhece que a maneira do discurso sapiencial abordar a natureza e a ação divina é exatamente a "mesma maneira que a literatura sapiencial do Antigo Oriente fala de Deus ou dos deuses" (PREUSS, 1981, p. 317). Pode-se tratar, portanto, de um distanciamento proposital: para falar de Deus do âmbito cotidiano seria necessário assumir certo grau da sua ausência, e atribuir a ele apenas o básico para intuir sua ação na vida comum.

\section{Considerações finais}

A teologia como linguagem humana em Rubem Alves poderá encontrar algumas intersecções com o discurso sapiencial da Bíblia. Longe de estabelecer uma revisão definitiva sobre o assunto, este trabalho preferiu limitar-se a três aspectos mais imediatos dessa relação: (1) a linguagem teológica como expressão do ser humano no mundo; (2) a linguagem teológica como diálogo; (3) a linguagem teológica como ausência de Deus. Sobre a primeira, tanto Rubem Alves quanto os textos sapienciais parecem oferecer um pensamento que considera as demandas e os desejos do corpo: suas incontáveis variações de humor, necessidades sexuais, assim como declarações desesperadas de angústia ou louvores de alegria. Esse aspecto antropológico imediato torna o texto sapiencial uma produção predominantemente humana; uma expressão sincera sobre sua relação com o mundo e suas expectativas a respeito de Deus. 
A segunda relação, a linguagem teológica como diálogo, evidencia a necessidade de se fazer teologia com a participação do "outro relevante", como atestado por Rubem Alves. O discurso sapiencial, longe de ser autocentrado, parece compartilhar compreensões teológicas de outros povos, além de, em algumas ocasiões, conferir voz direta e indiretamente ao discurso estrangeiro. Esse diálogo parece deixar esclarecer o aspecto "ecumênico" ou "universal" da teologia sapiencial, e seu desejo de encontrar a vontade de Deus em outras culturas. Seguindo uma lógica semelhante, por fim, a última relação versa sobre a linguagem teológica como ausência de Deus. A noção de Rubem Alves de que a teologia se realiza na cultura por uma consciência de ausência, e sua imediata vontade de preenchê-la com significado, pode ser evidenciada no discurso sapiencial, porém, de uma perspectiva meramente cotidiana. O Deus descrito pela sabedoria bíblica é basicamente aquele que ordena o funcionamento do mundo e julga as ações humanas. A ausência preenchida pelo discurso sapiencial é aquela que diz respeito ao lugar de Deus no cotidiano, e, por isso, estará igualada a muitos discursos que pretendem encontrá-lo no mesmo âmbito na sabedoria do AOM.

\section{Referências bibliográficas}

ALVES, Rubem. A gestação do futuro. 2. ed. Campinas: Papirus, 1987.

Da esperança. Campinas: Papirus, 1987.

. O enigma da religião. 3. ed. Campinas: Papirus, 1984.

. O que é religião?. 15. ed. São Paulo: Loyola, 2014.

O suspiro dos oprimidos. São Paulo: Paulus, 2006.

Prefácio: A beleza dos pássaros em vôo. In: CERVANTES-ORTIZ, Leopol-

do. A teologia de Rubem Alves: poesia, brincadeira e erotismo. Campinas: Papirus, 2005b.

. Religião e Repressão. São Paulo: Loyola, 2005a.

. Teologia do Cotidiano: meditações sobre o momento e a eternidade. São Paulo:

Olho d'água, 1994.

. Variações sobre a vida e a morte ou o feitiço erótico-herético da teologia. São Paulo:

Loyola, 2005.

BOSTRÖM, Lennart. The God of the sages: the portrayal of God in the Book of Proverbs.

Stockholm: Almqvist \& Wiksell, 1990.

BUSS, Martin J. Dialogue in and among genres. In: BOER, Roland (Ed.). Bakbtin and genre theory in biblical studies. Atlanta: Society of Biblical Literature, 2007.

CARMO, Felipe S. Gênero sapiencial em diálogo: uma leitura bakhtinana de Provérbios 22:17-24:22 e Ensinamentos de Amenemope. In: BRANCAGLION JR., Antonio; CHAPOT, Gisela (Orgs.). Semna - Estudos de Egiptologia IV. Rio de Janeiro: Klíne, 2017b.

. Revelação e cultura: reflexões bíblicas para o cotidiano. In: NOVAES, Allan

M.; CARMO, Felipe S. O adventista e a cultura pop. Engenheiro Coelho: Unaspress, 2017a. Sabedoria na Bíblia Hebraica: uma breve introdução ao gênero literário sapiencial.

Dissertação (Mestrado em Estudos Judaicos), Universidade de São Paulo, São Paulo, 2018. 
CERESKO, Anthony R. Introduction to Old Testament wisdom: a spirituality for liberation. New York: Orbids Books, 1999.

CERVANTES-ORTIZ, Leopoldo. A teologia de Rubem Alves: poesia, brincadeira e erotismo. Campinas: Papirus, 2005.

CLEMENTS, Ronald E. Wisdom in theology. Carlisle; Grand Rapids: The Paternoster Press; William B. Eerdmans Publishing Co., 1992.

CLIFFORD, Richard J. (Ed.). Wisdom literature in Mesopotamia and Israel. Atlanta: Society of Biblical Literature, 2007.

CLINES, David. Job's Fifth friend: an ethical critique of Book of Job. Biblical Interpretation, v. 12 , n. 3, p. 233-250, set., 2004.

CRENSHAW, James L. In search of divine presence: some remarks preliminary to a theology of wisdom. Review \& Expositor, vol. 74, n. 3, p. 353-369, 1997. Old Testament wisdom: an introduction. London: SCM Press, 1981.

CROWELL, Bradley L. A reevaluation of the edomite wisdom hypothesis. Zeitschrift für die Alttestamentliche Wissenschaft, vol. 120, n. 3, 2008.

DAY, John. Foreign Semitic influence on the wisdom of Israel and its appropriation in the Book of Proverbs. In: DAY, John; GORDON, Robert P.; WILLIAMSON, H. G. M. Wisdom in Israel. Essays in honour of J.A. Emerton. Cambridge: Cambridge Universty Press, 1995.

DELL, Katharine J. Deciding boundaries of "Wisdom": applying the concept of family resemblance. In: SNEED, Mark R. (Ed.). Was there a Wisdom Tradition?. New perspectives in israelites wisdom studies. Atlanta: SBL Press, 2015.

FEUERBACH, Ludwig. The Essence of Christianity. New York: Herper \& Row, 1957.

GAMMIE, John G.; PERDUE, Leo G. (Eds.). The sage in Israel and the ancient Near East. University Park, PA: Eisenbraus, 1990.

HASEL, Gerhard. Teologia do Antigo e Novo Testamento: Questões básicas no debate atual. São Paulo: Academia Cristã, 2012.

KYNES, Will. The "Wisdom literature" category: an obituary. The Journal of Theological Studies, vol. 69, n. 1, p. 1-24, abr., 2018.

The Nineteenth-Century Begnnings of "Wisdom Literature", and its twenty-first-century end? In: JARICK, John (Ed.). Perspectives on israelite wisdom. Proceedings of the Oxford Old Testament Seminar. London; New York: Bloomsburry T\&T Clark, 2016.

MARTINS, Gustavo C.; ALMEIDA, Edson F de. O canto do pássaro encantado: a religião como saudade em Rubem Alves. Estudos de Religião, vol. 31, n. 2, p. 2-19, mai-ago, 2017.

MENDES, Danilo; PY, Fábio. A teologia do cotidiano à luz da esperança: traços cristãos românticos em Rubem Alves. Estudos de Religião, v. 32, n. 2, p. 5-28, mai-ago, 2018.

MUCK, Burton L,; MURPHY, Roland E. Wisdom Literature. In: KRAFT, Robert A.; NICKELSBURG, George W. E. (Eds.). Early judaism and its modern interpreters. Georgia: Fortress Press, 1986. (The Bible and its Modern Interpreters)

NUNES, Antônio V. Etapas do itinerário reflexivo de Rubem Alves: a dança da vida e dos símbolos. In: NUNES, Antônio V. (Org.). O que eles pensam de Rubem Alves e de bumanismo na religião, na educação e na poesia. São Paulo: Paulus, 2007.

Teologia e filosofia em Rubem Alves: a metamorfose dos sentidos. In: CAR-

VALHO, Marcelo; FIGUEIREDO, Vinicius (Orgs.). Filosofia contemporânea: arte, ciências humanas, educação e religião. São Paulo: ANPOF, 2013. 
PERDUE, L. G. Wisdom literature: a theological history. Louisville: Westminster John Knos Press, 2007.

(Ed.). Scribes, sages, and seers: the sages in the Eastern Mediterranean wold.

Göttinen: Vandenhoeck \& Ruprecht, 2008.

PREUSS, Horst D. O conceito de Deus na sabedoria mais antiga de Israel. In: GERSTERNBERGER, Erhard S. (Org.). Deus no Antigo Testamento. São Paulo: ASTE, 1981.

REBLIN, Iuri A. Teologia: outros cheiros, outros sabores... A teologia na perspectiva crítica e poética de Rubem Alves: Caminhos para uma teologia do cotidiano. Dissertação (Mestrado em Teologia), Escola Superior de Teologia, São Leopoldo, 2007.

SCHELlENBERG, Annette. Don't Throw the Baby Out with the Bathwater: On the Distinctness of the Sapiential Understanding of the World. In: SNEED, Mark R. Was there a wisdom tradition?. New prospects in israelite wisdom studies. Atlanta: SBL Press, 2016.

SCHWANTES, Milton. Sabedoria: textos periféricos? Estudos de Religião, vol. 22, n. 34, p. 53-69, jan-fev, 2008.

SILVA, Anaxsuell F. da. As cores do crepúsculo: fabulação, teologia e literatura em Rubem Alves. Estudos de Religião, vol. 31, n. 2, p. 261-284, mai-ago, 2017.

SILVA, Valmor da. Deus na linguagem proverbial: análise do uso do nome de Deus em provérbios e expressões populares da Bíblia e da atualidade. Horižonte, vol. 14, n. 43, p. 890-908, jul-set, 2016.

SNEED, Mark R. Is the "Wisdom Tradition a Tradition? Catholic Biblical Quarterly, vol. 73, n. $50-71,2011$.

Is the "Wisdom Tradition" a Tradition? Catholic Biblical Quarterly, vol. 73, p.

50-71, 2011.

TERRIEN, Samuel. Jó. São Paulo: Paulus, 1994.

VÁZQUEZ BUENFIL, Luis. Rubem Alves y la teologia del cuerpo. In: CERVANTES-

-ORTIZ, Leopoldo. A teologia de Rubem Alves: poesia, brincadeira e erotismo. Campinas:

Papirus, 2005.

VELIQ, Fabiano. Dizer e viver a esperança: aspectos sobre linguagem e religião no pensamento de Rubem Alves. Reflexus, vol. 8, n. 12, 2014.

RAD, Gerhard von. Teologia do Antigo Testamento. Vols. 1 e 2. 2. ed. São Paulo: Associação de Seminários Teológicos Evangélicos, 2006.

WEEKS, Stuart. An introduction to the study of wisdom literature. London: T\&T Clark, 2010. Early israelite wisdom. Oxford: Oxford University Press, 2007.

WILLIAMS, James G. Provérbios e Eclesiastes. In: ALTER, Robert; KERMODE, Frank (Orgs.). Guia literário da Bíblia. São Paulo: Editora da Unesp, 1997.

Submetido em: 3-10-2018

Aceito em: 20-12-2018 